GA-A20623

\title{
THE ELECTRICAL INSULATION NOV 151991 OF THE DIII-D ADVANCED DIVERTOR ELECTRODE
}

by

J.P. SMITH, M.J. SCHAFFER, and A.W. HYATT

OCTOBER 1991

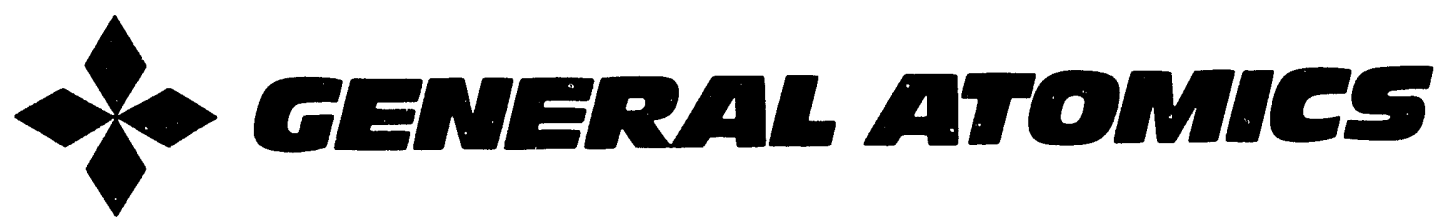




\section{DISCLAIMER}

This report was prepared as an account of work sponsored by an agency of the United States Government. Neither the United States Government nor any agency thereof, nor any of their employees, makes any warranty, express or implied, or assumes any legal liability or responsibility for the accuracy, completeness, or usefulness of any information, apparatus, product, or process disclosed, or represents that its use would not infringe privately owned rights. Reference herein to any specific commercial product, process, or service by trade name, trademark, manufacturer, or otherwise, does not necessarily constitute or imply its endorsement, recommendation, or favoring by the United States Government or any agency thereof. The views and opinions of authors expressed herein do not necessarily state or reflect those of the United States Government or any agency thereof. 


\title{
THE ELECTRICAL INSULATION OF THE DIII-D ADVANCED DIVERTOR ELECTRODE
}

\author{
by \\ J.P. SMITH, M.J. SCHAFFER, and A.W. HYATT
}

This is a preprint of a paper presented at the 14th IEEE Symposium on Fusion Engineering, September 30-October 3, 1991, San Diego, California, and to be printed in the Proceedings.

\author{
Work supported by \\ U.S. Department of Energy \\ Contract DE-AC03-89ER51114
}

\section{GENERAL ATOMICS PROJECT 3466} OCTOBER 1991

\section{GENERAL ATOMICS




\title{
THE ELECTRICAL INSULATION OF THE DIII-D ADVANCED DIVERTOR ELECTRODE
}

\author{
J.P. Smith, M.J. Schaffer, and A.W. Hyatt \\ General Atomics \\ P.O. Box 85608, San Diego, Catformia 92186-9784
}

Abstract: The electrode for biasing experiments on the DIII-D tokamak was installed in the summer of 1990 and biasing experiments have shown positive results. For the electrode, electrical insulation had to provide voltage standoff in the DIII-D divertor environment of neutral pressures in the range of $10^{-8}$ to $5 \times 10^{-2}$ torr, variable magnetic fields, and in the presence of ionizing radiation. The design approaches taken for this challenging application were described in Ref. 1. The electrical insulation system was designed and tested in air and vacuum for voltages up to $3 \mathrm{kV}$. In this paper, we provide an update on our operating experience, problems encountered, and improvements to the system. Electrical breakdown of some components has occurred during tokamak operations and transient voltages, up to $5 \mathrm{kV}$, have been observed. The original concept for insulating the water and electrical feeds for the electrode, a thin layer of woven ceramic cloth insulation between the feeds and a ground plane to keep out stray plasma, was found to be prone to failure. A new scheme of rigid ceramic insulators surrounded by a ground plane was designed and is being implemented. Another problem was ares from vessel potential surfaces to the electrode in several locations where vessel ground existed within $1 \mathrm{~cm}$ of the electrode. The are traveled in a small crack between two insulators. Careful atteation has been paid to closing this and other small gaps in the insulation. Coatings on the surface of plasma facing insulators have been found to be electrically conductive. Grooves are being machined into the insulators to give areas shadowed from the coating source. Tests are being done to demonstrate the design concepts in both vacuum and glow discharge environments. Plasma sprayed ceramic coatings were also tested to determine the voltage standoff capability in a glow plasma discharge. The results of these tests will be discussed.

\section{Introduction}

In the summer of 1990 , the first stage of the Advanced Divertor for DIII-D tokamak was installed (Fig. 1). One of the main components installed was an electrically isolated, toroidally continuous ring electrode. This electrode was powered by a $1.2 \mathrm{kV}, 20 \mathrm{kA}$ povrer supply and was designed to drive current in the scrape-off linyer. The purpose of the experiment was to study energy and particle transport modification, second stability limits, effects of edge current on $\mathrm{H}$-mode, and test helicity injection curreat drive. The second stage of the Advanced Divertor, a toroidally continuous cryo condensation pump, will be installed in late 1991.

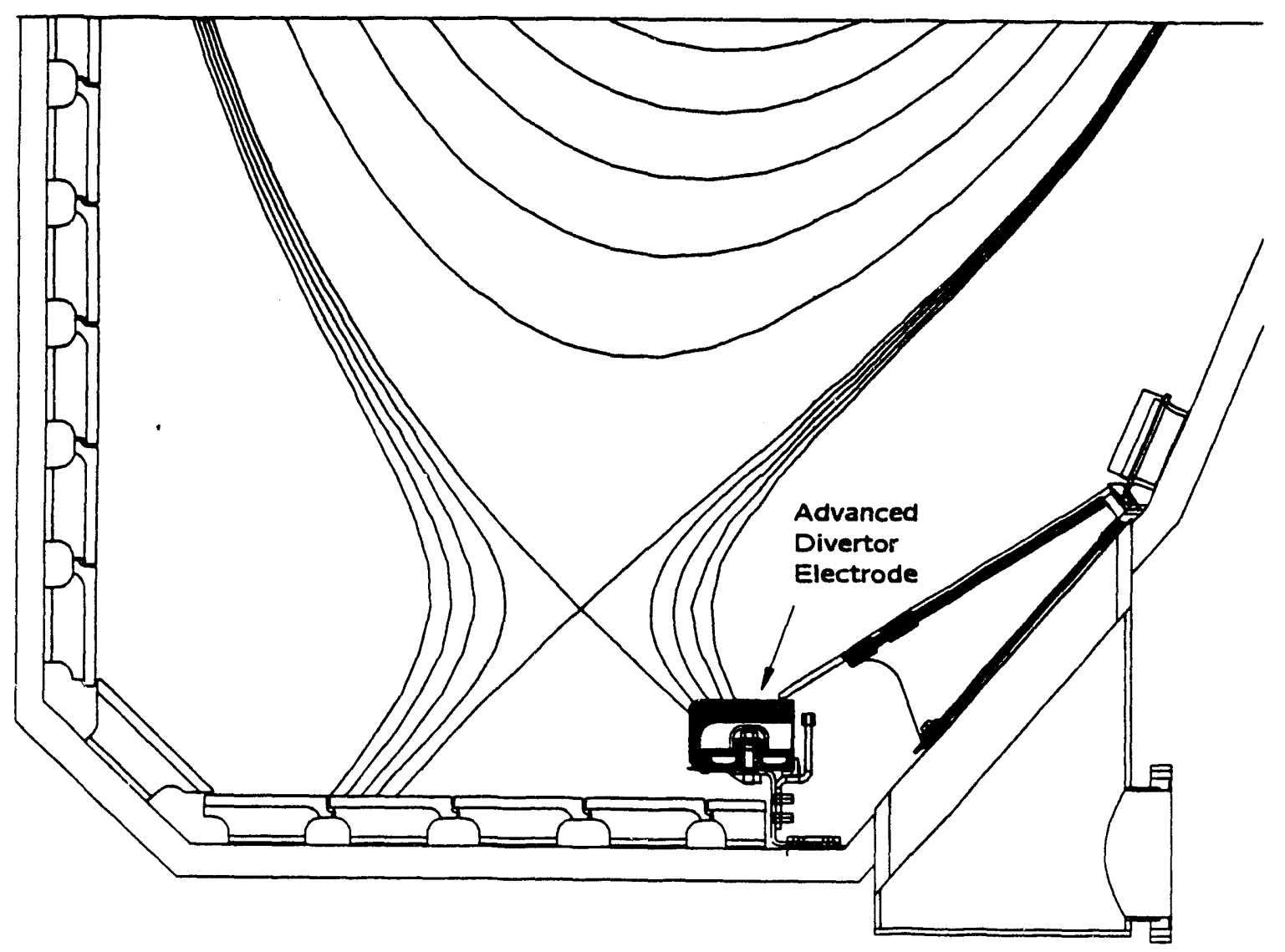

FIG. 1. Lower section of the DIII-D vacuum vessel with Advanced Divertor Electrode. 
To date the ring electrode has been biased to $550 \mathrm{~V}$ and $12 \mathrm{kA}$ of current. Promising results have been obtained in the areas of particle transport and H-mode threshold modification [2].

However, during operation several electrical problems did occur. The balance of this paper discusses the problems and the solutions implemented in September 1991.

\section{Operational Experience}

During initial start-up of the system, several electrical faults were found. These primarily occurred in the electrical and water feeds located in four positions around the vessel. The original approach to insulating these feed's was to wrap the lines with Nextel ceramic cloth and an over-wrap of a metal ground plane to keep out stray plasma. The over-wrap initially was thin strips of stainless steel but these cut through the Nextel and were replaced by stainless steel channels assembied onto the feeds over the Nextel wrap.

After the whole system was hi-potted to $3 \mathrm{kV}$, operations resumed. Ares were detected on current and voltage diagnostics. Voltage spikes up to $5 \mathrm{kV}$, but lasting as little as $2 \mu \mathrm{sec}$, were also detected. The voltage standoff of the system decayed slowly over time as did the insulation resistance. The system dropped to a standoff voltage of $1.2 \mathrm{kV}$ and held. Once, the system improved slightly to $1.5 \mathrm{kV}$ after baking to $300^{\circ} \mathrm{C}$.

An inspection vent was utilized to investigate the cause of the problems and to identify areas that required redesign. During the inspection vent, extensive hi-pot testing was done using six Rogowski coils attached to oscilloscopes to aid in identifying the locations of faults. Several items of interest were found.

The most significant problem was arcing between the ring and a ring support. Here, the grounded support was within $1 \mathrm{~cm}$ of the biased ring (Fig. 2). The arc occurred where the mica sheet on the bottom of the ring butted into the mica sheet on the outer side of the ring. No overlap in the insulation existed here. The are appeared to be a diffuse are traveling between the ring and a mica insulating sheet on the back of the ring. No damage was seen on the ring or graphite tiles, but a considerable amount of metal was melted of the support. The damage was seen at four adjacent locations of the 24 local ring supports. This arcing was not observed elsewhere in the machine.

The alumina heat shield on the bottom of the ring was found to be broken in two places. In one location, the piece was broken in half but remained in place. The other location had several pieces broken out. These pieces were swept under and behind the ring during plasma operation. Some of these pieces, heated to incandescence, were observed by an IR camera during several plasma discharges.

Another finding during the inspection vent was conductive coatings on the plasma facing insulators. The black to grey colored coatings had been observed in previous vents but the coatings had been highly resistive. The resistance of the coatings this time was much lower. During hi-pot testing, arcs were observed in the gap between the boron nitride insulator and the baffle plates and between the graphite tile and the insulator. The explanation for this was the arc jumping the small gaps and conducting through the coating on the surface of the insulators. This type of failure occurred at 1.5 to $1.8 \mathrm{kV}$ and prohibited testing to higher voltages. To enable further testing of the system, mylar sheets were inserted in the gap between the baffle plates and the insulators. The next area of breakdown discovered was

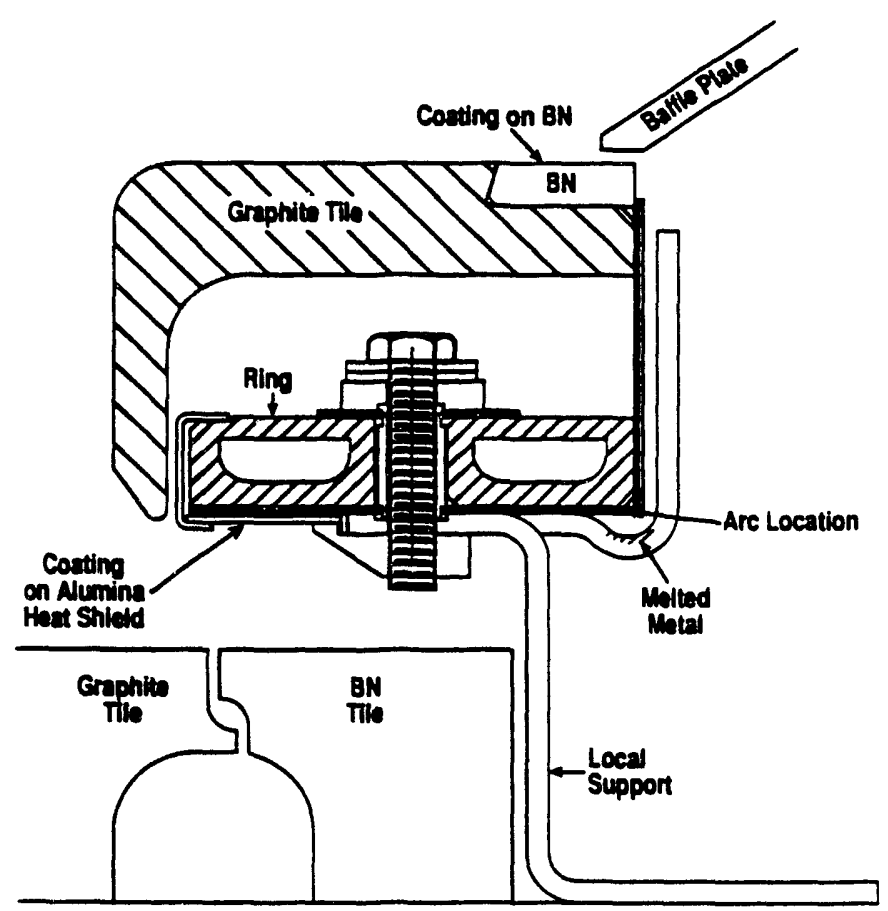

FIG. 2. Original design of the divertor ring insulation concept.

the alumina heat shield on the bottom of the ring. Once again ares were detected on either side of the alumina piece indicating a short arc path to a conductive coating and current passing through the conductive coating. These faults were also insulated with mylar to facilitate further testing. Coating samples were taken from the vessel. EDACS, SEM, and Auger analysis revealed that most of the coating was metal, particularly the metals that make up Inconel 625 , the material used for the outer vessel walls and baffle plates. Very little carbon (the material used on the centerpost and divertor target armor) was observed in the coating.

Once the surface tracking had been eliminated, a fault was located in one feedthrough location between the conductor and the ground can. This fault was cleared by moving the can around slightly and increasing the gap between a support and the ground can. At various times during hi-potting, other feedthroughs were suspect but repeatable results could not be obtained.

All plasma facing components did perform well. The boron nitride was neither damaged nor broken, although there was some slight erosion on the leading edges where exposed, and the graphite tiles showed no damage at all. Also, no faults were found in the insulated bolted joints of the ring to the grounded supports. These were individually tested up to $2 \mathrm{kV}$.

\section{Improvements}

A careful study of the system was completed using the information gained in the vent, and plans made to correct all known potential problems. Many new components were designed and built. The new insulation goal was set at $5 \mathrm{kV}$ in air and vacuum.

Arcing from the ring to its support was fixed by putting a machinable ceramic insulating angle continuously around the 
lower outer corner of the ring (Fig. 3). With the continuous insulating angle coverage, an arc to the vessel floor is also prevented. To do this, the support for the ring was redesigned to give enough space for the insulator. The insulator angle is made in 15-degree segments and is supported by a grounded metal angle. The metal angle also traps the insulator in place in case of cracking or breaking.

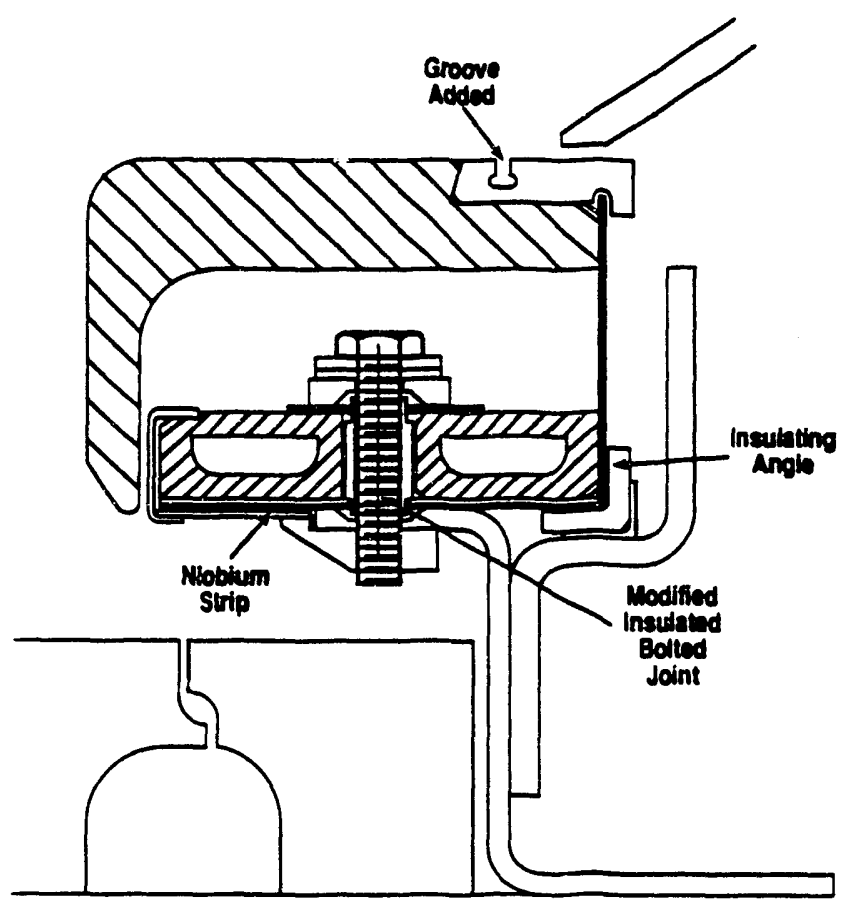

FIG. 3. New design of divertor ring insulation concept.

The main purpose of the alumina on the bottom of the ring is to provide a heat shield for the mica sheet insulator on the bottom of the ring. Cracking of the alumina is not a problem if it remains in place. Therefore, a strip of niobium was brazed on the back side of the alumina to bold it in place if it cracks. Niobium was chosen because of a close match in coefficient of thermal expansion to the alumina. The niobium strip floats electrically and is stopped short of all edges and sides of the alumina. Test pieces were made to demonstrate the principle.

An undercut groove was machined into the top surface of the boron nitride insulator on top of the ring to provide a region shadowed from coating. The outer edge of the insulator was modified to increase the leakage path to the baffle plate from below.

The most extensive part of the reinsulation of the ring electrode took place in the feeds and feedthroughs. A whole new concept was developed and implemented. The existing water feeds were reduced from eight separate feeds to two. The electric feeds remained at four but their configuration changed. Previously, the feeds were design to be flexible to handle the differential thermal expansion between the ring and the vessel. This required the electric feed to have several flexible midpoint supports to react the high electromagnetic forces. These midpoint supports complicated the insulation and were potential fault areas. The new design eliminated the midpoint supports by making the cross-section of the electric feed larger. Because the electric feed was no longer flexible enough to allow for the differential expansion, an extra bellows was added to the vacuum feedthrough to gain the flexibility required. All these modifications made the feeds much easier to insulate than originally.

The feed insulation is now entirely of hard ceramic. The feeds are surrounded by a ceramic box their entire length and covered by a metal ground plane (Fig. 4). The ceramic boxes are made in sections and the joints have a minimum $2.5 \mathrm{~cm}$ surface creep path to reach the metal ground plane. The insulation is held in place with spring clips.

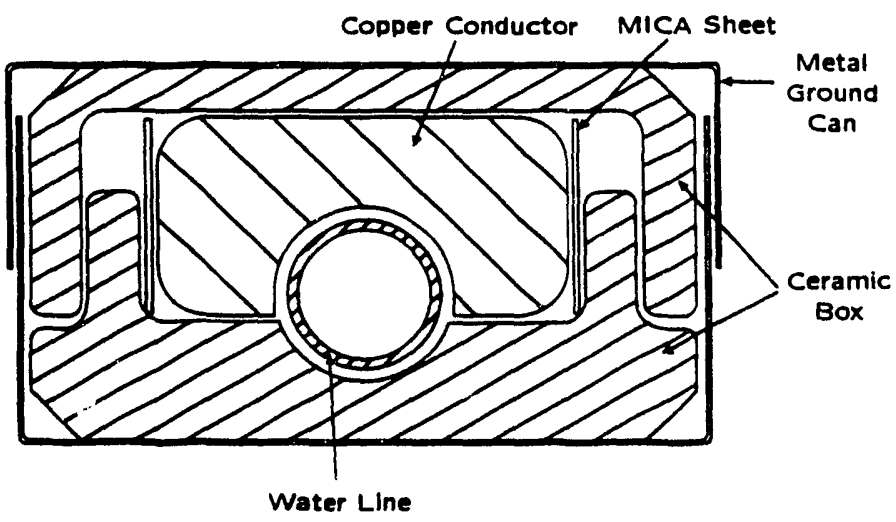

Fig. 4. Cross-section of new feeds.

The ring support insulated bolted joint design was modified for higher voltage standoff, even though no problems had been detected in the original design. Larger chamfers were added to the top and bottom of the holes through the ring, and the surface tracking paths were increased. The ring had the chamfer on the lower outer corner increased from 0.4 to $2 \mathrm{~mm}$.

Testing was completed on the improved bolted joint. The voltage standoff capability increased. Testing was also done on several plasma sprayed coatings. Three materials and two processes were considered. A titanium dioxide coating did not act as an insulator at all. A combined titanium dioxide/aluminum oxide coating acted as a highly resistive coating and a pure aluminum oxide coating was a good insulator. No difference could be seen between vacuum plasma sprayed material and standard plasma sprayed material. A summary of the testing can be seen in Table 1. The testing was done in a hydrogen glow discharge environment with a temperature of $1 \mathrm{eV}$ and density approximately $10^{11} \mathrm{~cm}^{-3}$. All of the alumina coatings had imbedded metal impurity particles and breakdown was believed to be facilitated by local concentration of these metal impurities. All breakdowns led to one or two small holes through the coating. The two samples of 0.02 in. alumina coating did not breakdown for any voltage up to the test maximum of $10 \mathrm{kV}$. The titanium dioxide/alumina coatings were highly resistive, with a unit surface conductivity roughly given by $\sigma=A \mathrm{~V}$, with $A \approx 6.8 \times 10^{-8} / \Omega$ $\mathrm{V}-\mathrm{cm}^{2}$ for the 0.01 in. coating.

These sprayed coatings were not used on the biased electrode or feeds due to the difficulty in verifying the quality of the insulation over large surface areas. The difficulty of in situ repair of the coating if damage was found or created diring installation also reduced the attractiveness of the coating. The coating is being considered ior low voltage insulation on the 
Table 1: Results of Insulated Coating Tests

\begin{tabular}{|l|c|c|}
\hline \hline Material & $\begin{array}{c}\text { Coating } \\
\text { Thickness } \\
\text { (in.) }\end{array}$ & $\begin{array}{c}\text { Voltage } \\
\text { Standoff } \\
(\mathrm{kV})\end{array}$ \\
\hline Pure Alumina & 0.005 & 1.3 \\
Pure Alumina & 0.01 & 5 \\
Pure Alumina & 0.02 & $>10.0$ \\
Titanium Dioxide & 0.005 & conductive \\
Titanium Dioxide & 0.01 & conductive \\
Titanium Dioxide & 0.02 & conductive \\
$13 \% \mathrm{TiO}_{2}, \mathrm{Al}_{2} \mathrm{O}_{3}$ & 0.005 & $1.5^{*}$ \\
$13 \% \mathrm{TiO}_{2}, \mathrm{Al}_{2} \mathrm{O}_{3}$ & 0.01 & $>8.0^{*}$ \\
$13 \% \mathrm{TiO}_{2}, \mathrm{Al}_{2} \mathrm{O}_{3}$ & 0.02 & $>10.0^{*}$ \\
VPS Alumina & 0.01 & 0.8 \\
VPS Alumina & 0.02 & $>10.0$ \\
\hline
\end{tabular}

*These coatings were highly resistive, drawing some current up to breakdown voltage.

cryocondensation pump for the Advanced Divertor [see Smith et al., The Design and Fabrication of a Toroidally-Continuous
Cryocondensation Pump for the DIII-D Advanced Divertor, this Symposium].

\section{Summary}

The insulation of the Advanced Divertor was upgraded after operational experience. Many components were changed after careful consideration and testing. The new system was designed to stand off $5 \mathrm{kV}$ in air or vacuum.

\section{Ackniwiedgment}

This is a report of work sponsored by the U.S. Department of Energy under Contract Ni. DE-AC03-89ER51114.

\section{References}

[1] J.P. Smith et al., "Di sign of DIII-D Advanced Divertor," in Proc. 14th Symp. sn Fusion Engineering, IEEE (1989), p. 1315.

[2] M.J. Schaffer et al. "Particle Control in the DIII-D Advanced Divertor," his Symposium. 

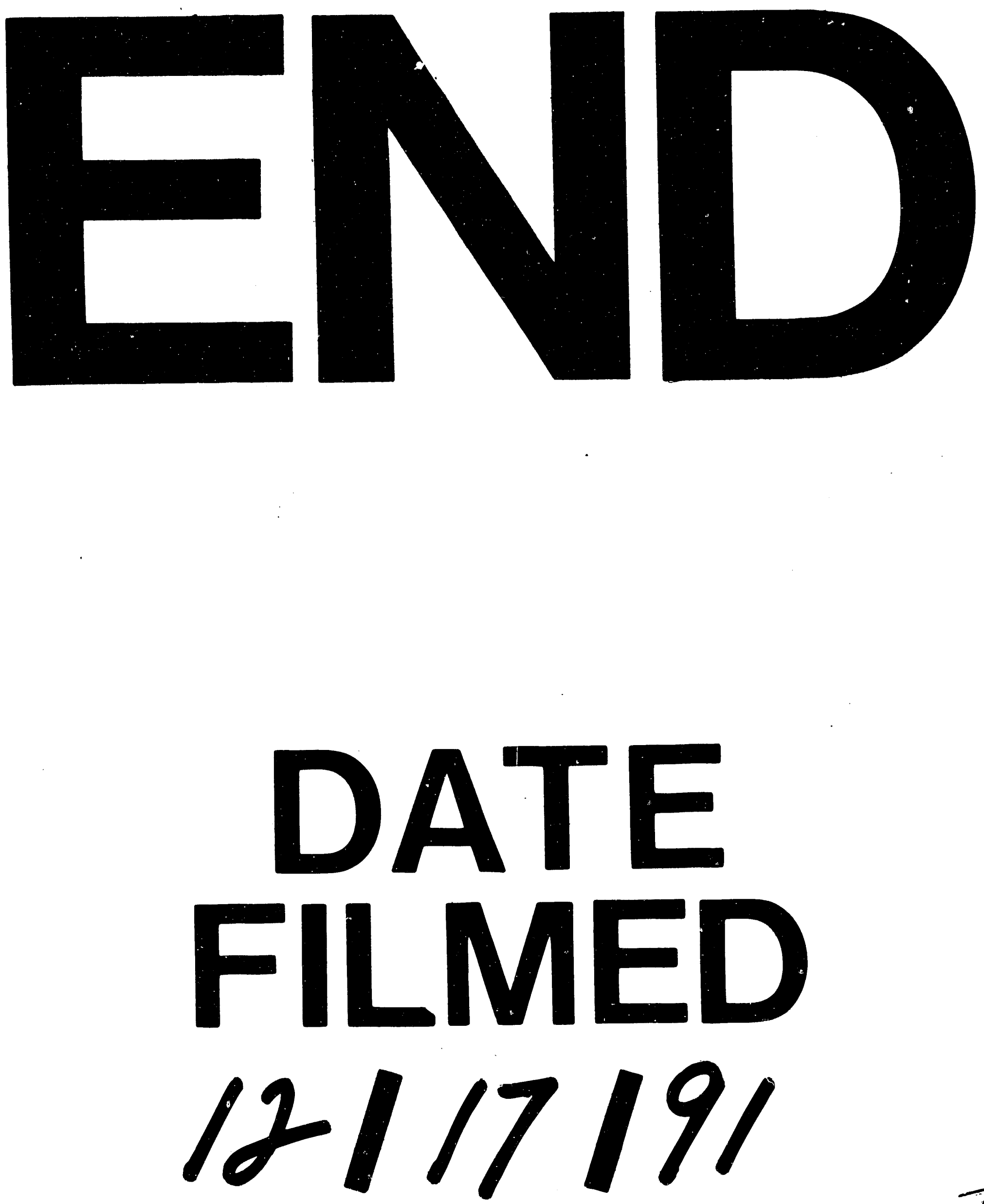
